\title{
PERCURSOS E FRONTEIRAS: OS LABIRINTOS ENTRE A PROTEÇÃO LEGAL E A SALVAGUARDA INSTITUCIONAL DAS COLEÇÕES ARQUEOLÓGICAS NO BRASIL
}

Paulo Otávio Laia ${ }^{1}$

\section{RESUMO}

O artigo aborda os instrumentos legais de preservação do patrimônio arqueológico no Brasil, buscando compreender, sob o ponto de vista museológico, os impactos das pesquisas arqueológicas sobre as instituições responsáveis pelas ações de guarda e pesquisa destes bens, com observações orientadas a discutir as relações que permeiam os distintos atores envolvidos neste processo. Diante dos temas tratados, busca-se ainda articular a Musealização da Arqueologia como uma abordagem conceitual e prática essencial para o fortalecimento dos procedimentos institucionais de gestão deste patrimônio.

PALAVRAS-CHAVE: patrimônio arqueológico, políticas públicas patrimoniais, musealização da arqueologia, coleções, licenciamento ambiental.

\section{ABSTRACT}

The article deals with the legal instruments for the preservation of archaeological heritage in Brazil, aiming to understand, from a museological perspective, the impacts of archaeological research on the institutions responsible for the guarding and researching of archaeological collections, with observations aimed at discussing the relations that work the different actors involved in this process. In view of the themes discussed, it is also sought to articulate the Musealization of Archeology as a conceptual and practical approach essential for strengthening institutional procedures for the management of this heritage.

KEYWORDS: archaeological heritage, heritage public policies, musealization of archeology, collections, environmental licensing process.

\section{RESUMEN}

El artículo aborda los instrumentos legales de preservación del patrimonio arqueológico en Brasil, buscando comprender, desde el punto de vista museológico, los impactos de las investigaciones arqueológicas sobre las instituciones responsables por las acciones de custodia e investigación de estos bienes, con observaciones orientadas a discutir las relaciones entre los distintos actores involucrados en este proceso. Ante los temas tratados, se busca aún articular la Musealización de la Arqueología como un abordaje conceptual y práctica esencial para el fortalecimiento de los procedimientos institucionales de gestión de este patrimonio.

PALABRAS CLAVE: patrimonio arqueológico, políticas públicas patrimoniales, musealización de la arqueología, colecciones, licenciamiento ambiental.

\footnotetext{
${ }^{1}$ Museólogo e Pesquisador do Laboratório de Pesquisas em Arqueologia, Patrimônio e Processos Museológicos Comunitários (LAPACOM) do Departamento de Museologia da Universidade Federal de Ouro Preto. E-mail: paulo.otavio.laia@gmail.com.
}

\begin{tabular}{|l|l|l|l|l|l|l|}
\hline (c) Rev. Arqueologia Pública & Campinas, SP & v.11 & n.2 & p. 166 & Novembro/2017 & ISSN 2237-8294 \\
\hline
\end{tabular} 


\section{INTRODUÇÃO}

Este artigo apresenta parte das considerações expostas no trabalho de conclusão do curso de graduação em Museologia da Universidade Federal de Ouro Preto, intitulado: Percorrendo Labirintos: diretrizes e impactos do endosso institucional nos processos de musealização do patrimônio arqueológico, orientado pelas Professoras Dra. Marcia Arcuri Suñer, da Universidade Federal de Ouro Preto, e Dra. Camila Azevedo de Moraes Wichers, da Universidade Federal de Goiás.

As discussões propostas pelo trabalho em questão abrangeram os processos de formação, pesquisa e gestão dos bens patrimoniais de natureza arqueológica, que, no Brasil, haja vista sua categoria de bens da União, resultam em tratamentos que se orientam a partir de uma série de normas jurídico-administrativas refletidas sobre os procedimentos de sua tutela, seja por meio de prerrogativas patrimoniais ou por determinações ambientais.

O panorama brasileiro, quanto ao assunto, apresenta-se atualmente em um complexo cenário envolvendo as pesquisas arqueológicas e o experimentado contexto desenvolvimentista que impulsionou os processos de licenciamento ambiental no país. As atividades de pesquisa, gestão e extroversão do patrimônio arqueológico brasileiro orientam-se, em sua grande maioria, por normas e instrumentos que determinam suas práticas, em que novos cenários exigiram também a adoção de novas perspectivas protecionistas, expostas em portarias, ordens de serviço e ferramentas de orientação administrativa.

O marco legal vigente (Lei $n-3.924 / 1961$ ) define que a guarda do material encontrado em atividades prospectivas, interventivas e de escavação está a cargo de instituições capazes de zelar por seu acondicionamento, conservação, investigação e difusão. A concretização deste processo e a possibilidade de salvaguarda dos materiais gerados pelas pesquisas se dão por meio de uma cadeia operatória, na qual parte do processo concentra-se na emissão do endosso institucional - declaração conferida pela instituição receptora do material arqueológico -, e continua na entrega do material à instituição que assume a responsabilidade da guarda desses bens, e que não necessariamente será a mesma apresentada no endosso. Nas formalidades do órgão gestor do patrimônio arqueológico, o Instituto do Patrimônio Histórico e Artístico Nacional (IPHAN), estes locais atualmente são denominados "instituição de guarda e pesquisa".

Diante disso, prima-se para que estas instituições sejam, em sua maioria, museus e centros científicos com vocação para a pesquisa e fruição das coleções arqueológicas. Todavia, como aponta Cristina Bruno (2014), os enlaces entre as instituições de guarda e pesquisa de acervos arqueológicos, no Brasil, e a prática do endosso institucional referente 
à salvaguarda destes acervos apresentam-se através de complexos percursos e, diante a tal condição, lança-nos o seguinte questionamento: por onde nos levam esses caminhos labirínticos?

Longe de responder à pergunta realizada pela pesquisadora acima mencionada, que com destaque dedicou grande parte de sua atuação acadêmica e profissional ao desenvolvimento de formulações e propostas voltadas a esta temática - incluindo a formação de gerações de pesquisadores inclinados na mesma tarefa -, o presente trabalho busca percorrer timidamente alguns desses labirintos, reunindo considerações que colaborem no processo de fortalecimento das instituições de preservação do patrimônio arqueológico brasileiro, considerando a Musealização da Arqueologia como um instrumento aplicado a este fortalecimento.

\section{AGENTES E TRAJETÓRIAS DO PATRIMÔNIO ARQUEOLÓGICO}

O panorama de preservação do patrimônio arqueológico no Brasil constitui-se a partir de perspectivas diversas que revelam, de certo modo, o pensamento preservacionista do tempo em que foram elaboradas. Assim, observamos a Lei no 3.924/1961 e os mecanismos a ela subsequentes, como: a Resolução CONAMA no 01/1986; as Portarias IPHAN no 07 de 1988 e no 230 de 2002; a Portaria Interministerial no 60/2015, a Instrução Normativa IPHAN no 01 de 2015; e, mais recentemente, as Portarias IPHAN no 195/2016, 196/2016, 197/2016 e a Ordem de Serviço no 02/2016. Tais instrumentos, respondendo a especificações patrimoniais e/ou ambientais, constituíram-se a partir das lacunas deixadas por normas anteriores, sempre na tentativa de organizar as tensões relativas à arqueologia brasileira.

Nesse sentido, a Lei 3.924/1961 configura-se como a norma matriz de um sistema protetivo do patrimônio arqueológico no país, visto que "traz um conteúdo específico, estabelece os conceitos próprios da matéria e atribui ao IPHAN a competência para o exercício de seu poder de polícia administrativa" na proteção desta categoria de bem cultural (SOARES, 2007, p. 68). Esses elementos a caracterizam como a principal ferramenta pública de gestão e proteção do patrimônio arqueológico brasileiro, e mesmo não sendo regulamentada após mais de cinquenta anos de sua promulgação, ela se apresenta como uma medida cautelar determinante frente aos impactos diversos que atingem este bem, como se verá adiante.

Com a ampliação da caracterização dos procedimentos socioambientais como um fenômeno que integra, na própria concepção de meio ambiente, a ideia de patrimônio cultural e de direitos culturais, promovida pela Constituição Federal de 1988, o patrimônio 
arqueológico insere-se também em outro sistema protetivo, no qual as técnicas, procedimentos ou normas específicas da arqueologia se somam aos princípios orientadores estabelecidos a partir da Lei da Política Nacional de Meio Ambiente (Lei no 6.938/81).

A partir dos anos 2000, principalmente com programas governamentais de aceleração e expansão das obras de infraestrutura nacionais, as pesquisas arqueológicas de natureza preventiva se desenvolveram de tal modo que, já no final de sua primeira década, corresponderam a $98 \%$ dos estudos arqueológicos realizados no Brasil (ZANETTINI, 2009 apud MORAES WICHERS, 2010, p. 174). Este fato nos possibilita afirmar, com determinada segurança, que nenhum acervo patrimonial ascendeu quantitativamente de forma tão expressiva nos últimos anos quanto o arqueológico.

A condição das ações de preservação do patrimônio arqueológico frente a este cenário consolidou o que Saladino (2013-2014, p. 57) denomina arena, onde distintos atores defendem diversos interesses, sendo estes, muitas vezes conflitantes. De acordo com Zanettini (ZANETTINI, 2010; ZANETTINI e MORAES WICHERS, 2014), a partir do conceito de "cadeia produtiva" da arqueologia, observa-se que estes atores se constituem igualmente em diversas esferas, como: os órgãos de gestão e fiscalização, as instituições de ensino formal e desenvolvimento científico em arqueologia, os profissionais da área (sejam eles arqueólogos autônomos ou inseridos em empresas), os órgãos de fomento, os empreendedores responsáveis pela implantação das obras de impacto e, consequentemente financiadores das pesquisas arqueológicas de caráter preventivo, as entidades de guarda e pesquisa dos acervos arqueológicos, e por fim, a sociedade, na medida em que grupos, coletivos, movimentos e comunidades constituem-se enquanto agentes sociais e, conjuntamente às demais entidades, são responsáveis pela preservação do patrimônio arqueológico.

Para o foco das discussões aqui propostas, o conjunto desses atores apresenta-se condensado no diagrama da figura 1, isto ocorre não por uma desconsideração dos demais agentes, mas pela tentativa de se configurar uma abordagem que observe diretamente os impactos decorrentes das relações específicas que se dão entre o IPHAN (órgão de gestão e fiscalização), a comunidade arqueológica ${ }^{2}$ (arqueólogos e arqueólogas, muitos/as deles articulados pela Sociedade de Arqueologia Brasileira - SAB -, mas não exclusivamente representados/as por meio dela), os empreendedores dos projetos de impacto (financiadores das pesquisas no âmbito do licenciamento ambiental), as instituições de guarda e pesquisa (entidades operacionais de preservação) e a sociedade diretamente relacionada (grupos, coletivos, movimentos sociais e comunidades).

${ }^{2}$ Considerando a atuação científica e profissional dos agentes da arqueologia brasileira.

\begin{tabular}{|l|l|l|l|l|l|l|}
\hline (c) Rev. Arqueologia Pública & Campinas, SP & v.11 & n.2 & p. 169 & Novembro/2017 & ISSN 2237-8294 \\
\hline
\end{tabular} 
FIGURA 01 - DIAGRAMA DAS ENTIDADES ENVOLVIDAS NOS PROCESSOS DE PRODUÇÃO E PRESERVAÇÃO DA ARQUEOLOGIA NO BRASIL

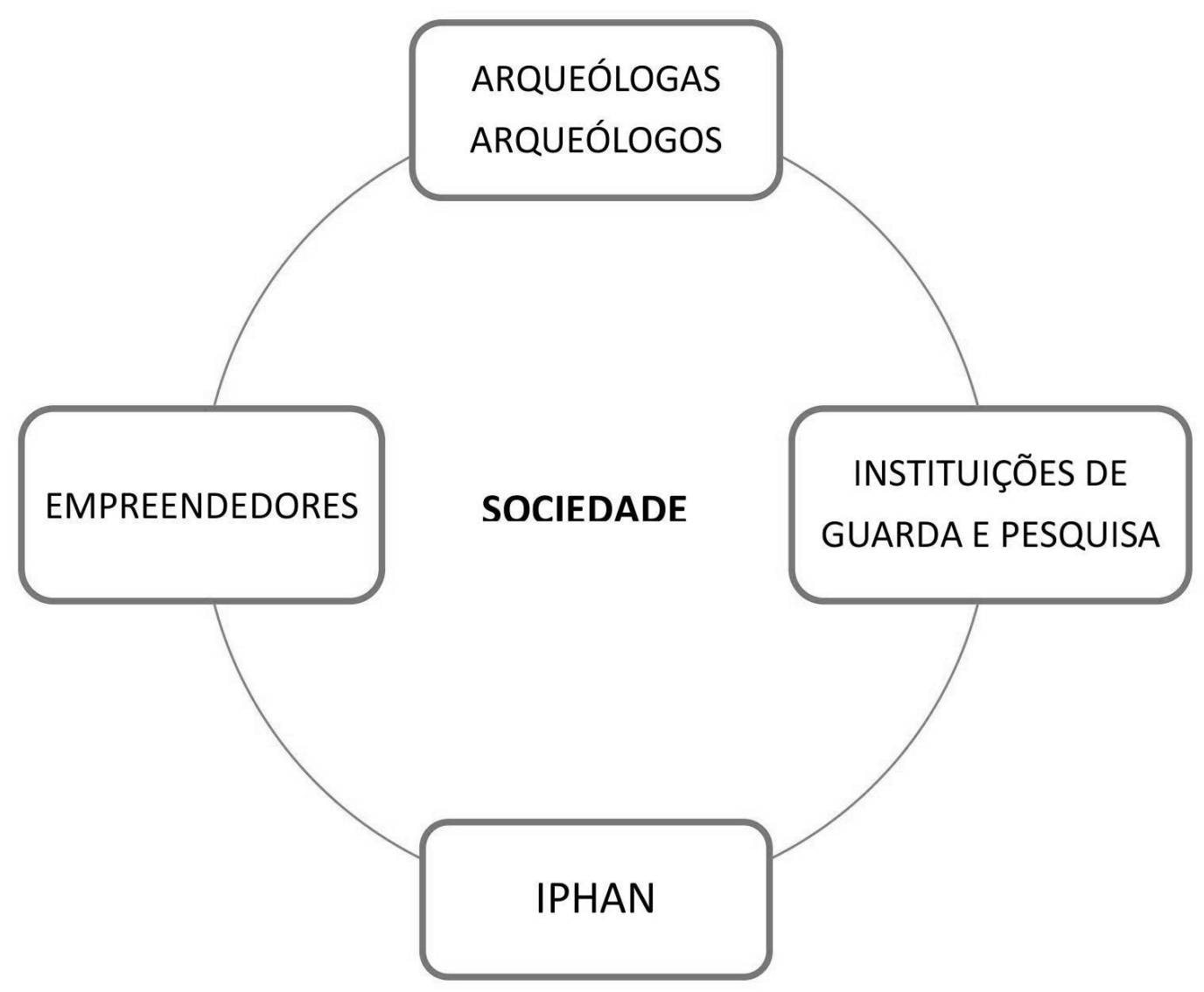

Esquema adaptado a partir de ZANETTINI, 2010 e ZANETTINI e MORAES WICHERS, 2014.

Nos processos e tensões entre patrimônio arqueológico e a sociedade, a atuação do IPHAN confunde-se entre seu modelo institucional de organização reguladora, fiscalizadora e de poder de polícia, com as demandas de um órgão público a serviço da sociedade, tendo de lidar, como aponta Meneses (2007, p. 40), com os novos conceitos que formam os discursos do patrimônio cultural e a ampliação de abordagens que considerem, por exemplo, a educação, a valorização, o fomento, a preservação física, a participação social e as pressões do mercado, que fazem frente ao setor patrimonial no seio de um programa desenvolvimentista nacional. 
Quanto à organização científica da arqueologia no país, sua agenda política e as tensões enfrentadas no tocante ao reconhecimento de um conjunto de ações efetivas à preservação do patrimônio arqueológico são verificadas mesmo antes da fundação da SAB na década de $1980^{3}$. Todavia, como colocam Schaan e Bezerra (2009), a criação desta configura-se num momento de "perda da inocência" da disciplina, que passa a considerar de modo mais abrangente a diversidade dos aspectos epistemológicos e, sobretudo, políticos (SCHAAN e BEZERRA, 2009, p. 07), mancando atualmente o papel desempenhado por esta Sociedade no escopo das deliberações acerca do patrimônio arqueológico brasileiro.

Assim, na "arena" colocada por Saladino (2013-2014), observa-se que a relação entre o IPHAN e a arqueologia no Brasil, ainda que compartilhem valores comuns, caracteriza-se como um processo no qual a circulação de distintas e, eventualmente, dissonantes intenções, resultou em constrangimentos e oportunidades (id., ib., p. 57), visto que o contexto geral onde se estabelecem estas tensões se apresenta condicionado a uma lógica de relativo distanciamento entre os seguimentos sociais e o sistema político, ou seja,

\begin{abstract}
ainda que os agentes diretamente envolvidos com o setor cultural, especificamente com o patrimônio, procurem atender às demandas e se adaptar à era da mercantilização da cultura, atuando no sentido de transformar os patrimônios em efetivos meios de mudança e desenvolvimento social, esta não parece ser uma questão de ordem para as autoridades brasileiras. [...] A problemática da preservação e da ausência de políticas específicas de preservação podem ser consideradas indícios de que o patrimônio cultural, mesmo com a atuação de organizações como o IPHAN e a existência de disposições legais em prol de sua valorização e preservação, ainda não é um elemento considerado de forma plena pela agenda política. (id., ib., p. 56).
\end{abstract}

Sendo este um terreno fértil para inúmeras discussões, não se pretende esgotar, aqui, as matizes desse relacionamento, mas, ao contrário, inserir um novo agente a esse círculo de tensão, direcionando a linha do debate às instituições de guarda e pesquisa do patrimônio arqueológico.

\footnotetext{
${ }^{3}$ A fundação da Sociedade de Arqueologia Brasileira ocorreu na cidade de Goiânia, no dia 28 de março de 1980, a partir da reunião de arqueólogos brasileiros por ocasião do Terceiro Seminário Goiano de Arqueologia, que prosseguiu com as discussões sobre a criação da referida Sociedade, iniciadas na Primeira Jornada Brasileira de Arqueologia (Rio de Janeiro - 1978) e na Segunda Jornada Brasileira de Arqueologia (Rio de Janeiro - 1979). SCHMITZ, P. I. A Sociedade de Arqueologia Brasileira: a fundação e os primeiros mandatos. SHAAN, D. P.; BEZERRA, M. (orgs.). Construindo a Arqueologia no Brasil: a trajetória da Sociedade de Arqueologia Brasileira. Belém: GKNoronha, 2009. 300 p.
}

\begin{tabular}{|l|l|l|l|l|l|l|}
\hline (C) Rev. Arqueologia Pública & Campinas, SP & v.11 & n.2 & p. 171 & Novembro/2017 & ISSN 2237-8294 \\
\hline
\end{tabular}


Compostas de museus ${ }^{4}$, centros culturais, memoriais, unidades universitárias, laboratórios e centros de pesquisa, que figuram entre todas as esferas da administração pública e privada, as referidas instituições são observadas a partir da complexa trama formada pelas demandas do processo de licenciamento ambiental e dos mecanismos legais de preservação vigentes. Insere-se à discussão também os diversos grupos sociais e suas demandas, encarregados, dentre outras coisas, de reivindicar junto a tais instituições sua participação na cadeia operatória transformadora dos suportes materiais da arqueologia em potencial vetor de valores sociais.

Sob os aspectos legais, a relevância de salvaguarda do material arqueológico proveniente das atividades de arqueologia figura inicialmente na Lei $n^{\circ}$ 3.924/1961, quando seu artigo 16 (parágrafo único) estabelece a obrigatoriedade de comunicação à Diretoria do Patrimônio Histórico e Artístico Nacional sobre a realização de escavações arqueológicas ou pré-históricas, determinando também a apresentação dos resultados obtidos e o destino do material coletado. Quando a Portaria IPHAN no 07/1988 é implantada, no intuito de organizar as atividades de pesquisa previstas pelo texto legal anterior, já se normatiza que os pedidos de permissão para autorização de pesquisas e escavações arqueológicas devem indicar, quando necessário, a instituição científica que apoia o projeto, apoio este expresso através da "declaração de endosso institucional" (art. $5^{\circ}$, inc. VII). A Portaria ainda deixa explícito que serão rejeitados os projetos que não apresentarem garantia de guarda do material recolhido (parágrafo $1^{\circ}$ ).

Quando do estabelecimento de diretrizes que orientam a relação entre as pesquisas arqueológicas e as demandas levantadas pelos processos de licenciamento ambiental, a Portaria IPHAN 230/2002 vai além, indicando em seu artigo 06으 (§ 8º) que a responsabilidade de guarda dos vestígios arqueológicos encontrados deverá ser garantida pelo empreendedor. O referido texto aponta que tal garantia deverá ser constituída a partir da modernização, ampliação e fortalecimento das "unidades museológicas" já existentes nas áreas, regiões ou municípios onde forem realizadas as pesquisas arqueológicas, sugerindo, ainda, a construção de novas unidades específicas para o caso.

Destacam-se neste momento alguns pontos relevantes no tratamento dos processos legais de proteção dos vestígios arqueológicos. O primeiro é o próprio reconhecimento das

\footnotetext{
${ }^{4} \mathrm{O}$ conceito de "museu" ou "instituições museológicas" abordado neste trabalho ancora-se na perspectiva estabelecida legalmente. Assim, de acordo com o artigo 1으, da Lei no 11.906/2009: "Consideram-se museus, para os efeitos desta Lei, as instituições sem fins lucrativos que conservam, investigam, comunicam, interpretam e expõem, para fins de preservação, estudo, pesquisa, educação, contemplação e turismo, conjuntos e coleções de valor histórico, artístico, científico, técnico ou de qualquer outra natureza cultural, abertas ao público, a serviço da sociedade e de seu desenvolvimento. Parágrafo único. Enquadrar-se-ão nesta Lei as instituições e os processos museológicos voltados para o trabalho com o patrimônio cultural e o território.
}

\begin{tabular}{|l|l|l|l|l|l|l|}
\hline ○ Rev. Arqueologia Pública & Campinas, SP & v.11 & n.2 & p. 172 & Novembro/2017 & ISSN 2237-8294 \\
\hline
\end{tabular} 
instituições de guarda no complexo processo do licenciamento ambiental, sendo a tais confiado o destino final do material recolhido. Este reconhecimento, entretanto, só se evidencia como consequência do avanço conceitual que tal sentença representa, visto que, como se verifica na prática, a importância demonstrada no texto legal não efetiva a inserção concreta dessas instituições no processo licenciatório como um todo, fazendo-as figurar apenas como um elemento passivo e burocrático.

O segundo ponto que se acentua no texto mencionado é a utilização do termo "unidade museológica" para se referir às instituições de guarda do material arqueológico, enquanto a norma anterior (Portaria IPHAN no 07/1988) menciona o endosso declarado por uma instituição científica. Não se pretende com esta observação realizar um questionamento sobre o caráter científico assumido pelos museus ao longo da história de sua formação. No Brasil, por exemplo, notáveis instituições museológicas, incluindo as de caráter nacional, surgiram a partir de centros especializados de pesquisa científica. O que se chama a atenção neste momento é o incipiente reconhecimento, no texto legal, dos museus como locais potencialmente indicados para a efetiva destinação dos acervos arqueológicos, já que, como se verificará mais adiante, estas instituições apresentam condições específicas para trabalhar tais acervos perante toda sua complexidade, indo desde a salvaguarda até a sua comunicação (BRUNO, 2006, p. 15), sendo necessário, portanto, o investimento no setor.

Este contexto é alterado com a publicação da IN IPHAN no 01/2015, que regulamenta a atuação do órgão a partir da Portaria Interministerial no 60/2015 e revoga a Portaria $n^{\circ}$ 230/02. Neste instrumento, o termo "unidade museológica" extingue-se, abrindo espaço para a sentença "instituições de guarda e pesquisa". Se por um lado esta alteração representa certa abrangência, na medida em que viabiliza o destino final do material arqueológico a diversas instituições que se responsabilizem tanto por sua guarda quanto pela produção de conhecimentos a partir dele, por outro, observa-se certa limitação quanto aos processos de socialização do patrimônio arqueológico, tendo em vista que, as instituições museológicas, especializadas ou não em arqueologia, possuem especificidades para o desenvolvimento das operações de salvaguarda e comunicação (id., ib.,), que podem ser aplicadas a estes bens.

A princípio, a modificação desses termos pode ser considerada como uma simples alteração de nomenclatura, já que o objetivo final da proposta é garantir a preservação dos bens arqueológicos em locais apropriados. Entretanto, ao se lançar um olhar criticamente direcionado para essa questão, observa-se que a mudança do termo "unidades museológicas" para "instituições de guarda e pesquisa" indica um marcador político fixado 
pelo órgão gestor desse patrimônio para definir precisamente as fronteiras de sua atuação. Se o IPHAN considerasse as "unidades museológicas" do país como as instituições mais indicadas para a recepção do patrimônio arqueológico, especialmente aqueles provenientes das pesquisas realizadas no âmbito dos processos de licenciamento ambiental, ele estaria ajuizando, também, a inserção desse patrimônio no sistema organizacional que regulamenta o setor museológico, ou seja, os processos que constituem os bens arqueológicos estariam igualmente submetidos à apreciação do Instituto Brasileiro de Museus (IBRAM) ${ }^{5}$.

É válido inferir neste momento que essa autarquia federal sucedeu o IPHAN nos direitos, deveres e obrigações relacionados aos museus em âmbito nacional, e, como qualquer outra unidade da governança pública, o IBRAM possui determinações próprias que, positiva ou negativamente, se aplicadas às coleções arqueológicas, certamente alterariam as atuais conjunturas em que estas se encontram. No que corresponde ao cenário dos processos de licenciamento, por exemplo, as tensões entre esses órgãos são veladas pelo silenciamento de um, em detrimento à demarcação das fronteiras políticas do outro.

Como apontado, de acordo com o formato de operação do patrimônio arqueológico, este pode se configurar como um instrumento potencialmente vetor de valores sociais e identitários. Sendo assim, os processos de reapropriação cultural por ele suscitados podem se estabelecer como ferramentas de domínio dos territórios, dos discursos sociais e das memórias aos quais estes possam estar vinculados.

$\mathrm{Na}$ medida em que essa reapropriação dos artefatos pelos cidadãos envolve uma relação de poder, a mediação do artefato arqueológico adquire importância crucial. Assim, discussões relativas ao o quê conservar, em qual instituição, com quais condições de acessibilidade e, ainda mais, quanto à propriedade científica do material, dizem respeito a todo um conjunto de questões ligadas aos artefatos. (FUNARI, 2003, p. 35).

Por esse ângulo, o principal descaminho trilhado pelo patrimônio arqueológico não diz respeito somente à sua jurisdição perante novas tutelas administrativas, mas sob as relações que o distanciam das possibilidades de mediação pela atuação da Museologia (MORAES WICHERS, 2010). O não convite à participação oficial desta área, por meio das políticas públicas de preservação do patrimônio arqueológico, só reforça o alargamento das margens entre os saberes e fazeres da Arqueologia, da Museologia e da sociedade. Logo, verifica-se a necessidade de um maior estreitamento entre as competências técnicas e os

${ }^{5} \mathrm{O}$ Instituto Brasileiro de Museus foi criado em janeiro de 2009, com a assinatura da Lei oㅜ 11.906, atualmente regulamentada pelo Decreto $\mathrm{n}^{\circ} \mathbf{8}$ 8.124, de 17 de outubro de 2013.

\begin{tabular}{|l|l|l|l|l|l|l|}
\hline (c) Rev. Arqueologia Pública & Campinas, SP & v.11 & n.2 & p. 174 & Novembro/2017 & ISSN 2237-8294 \\
\hline
\end{tabular} 
posicionamentos políticos assumidos pelo IPHAN e pelo IBRAM, uma vez que acima das vaidades administrativas deve estar disposta a garantia de preservação coletiva e o interesse público sobre esses bens.

Seguindo os interesses de participação das instituições de guarda e pesquisa, tomemos também como ponto de análise as determinações inferidas através da recente Portaria IPHAN no 196/2016, que se apresenta como um documento base na orientação do IPHAN, dos pesquisadores, das instituições de guarda e pesquisa e dos demais agentes envolvidos na gestão e na conservação dos bens arqueológicos, apresentando os requisitos mínimos a serem considerados e atendendo ao trinômio: pesquisa, conservação e socialização.

A portaria em questão institui as Recomendações para Conservação de Bens Arqueológicos Móveis e cria o Cadastro Nacional das Instituições de Guarda e Pesquisa e a Ficha de Cadastro de Bem Arqueológico. Dentre os pontos de maior relevância de tais recomendações, apresenta-se, por exemplo, a desejável participação de um profissional da área de conservação a partir da etapa de campo e não somente nas análises de laboratório. Orienta-se também a consultoria de educadores, museólogos, antropólogos etc., a fim de reunir dados que contextualizem a pesquisa e o acervo gerado, registrando as escolhas e metodologias do trabalho arqueológico, permitindo que futuramente possam ser elaboradas formas de extroversão dos dados produzidos pela pesquisa. $O$ mesmo se aplica às instituições, onde se espera a formação de uma equipe interdisciplinar que reúna arqueólogos, conservadores, museólogos, educadores etc., para que se concretize o trinômio acima mencionado. Apesar do avanço, a utilização de termos como "desejável" ou "consultoria de profissionais" abre margem para continuidade de uma série de descaminhos, já há muito praticados na arqueologia brasileira.

Outro ponto determinante da portaria diz respeito à capacidade estrutural das instituições na recepção de material, advertindo que as instituições deverão endossar e receber apenas aqueles bens que apresentem condições de conservar, dada formação de sua equipe técnica ou mesmo os espaços disponíveis para as condições de guarda. Recomenda-se também que estes locais não se limitem à guarda de acervos, mas que sejam capazes de incentivar e promover pesquisas sobre seus acervos e desenvolver ações de extroversão, como exposições, publicações, ações educativas etc.

Frente ao contexto apresentado, infere-se que os procedimentos técnicoadministrativos pelos quais está submetido o patrimônio arqueológico, singularmente no que se refere aos processos de sua salvaguarda, comunicação e gestão, sejam por meio das pesquisas arqueológicas no geral, mas principalmente sobre aquelas empreendidas no 
âmbito do licenciamento ambiental, constituem-se a partir de uma estratégia de preservação patrimonial composta e chancelada por meio dos diversos instrumentos de proteção legal deste bem e de suas respectivas aplicabilidades técnicas, que em conjunto, fundamentam o diagrama de produção e preservação da arqueologia no Brasil, acima apresentado.

A observação dessa trajetória faz-se necessária para evidenciar a relevância do papel desempenhado pelas instituições de guarda do material arqueológico, responsáveis pelo intermédio de um processo que se inicia nas fases preliminares de implantação de um empreendimento e culmina no reconhecimento do potencial de sociabilidade deste bem.

O que se observa, no entanto, é um desequilíbrio latente e desafiador para a atual gestão do patrimônio arqueológico no Brasil, gerado a partir da ausência de uma Política Pública Nacional que delibere efetivamente a respeito do tratamento dispensado ao patrimônio arqueológico no país. Os instrumentos jurídico-administrativos descritos até então funcionam como ferramentas de trabalho que "apagam incêndios" das tensões geradas pela carência de uma base legal sólida, abrindo margem, por exemplo, à esporádica ou quase nula participação das instituições de guarda e pesquisa nas etapas deliberativas dos processos de licenciamento ambiental.

\section{A MUSEALIZAÇÃO DA ARQUEOLOGIA COMO AMPLIAÇÃO DAS ABORDAGENS}

Ao se debruçar sobre o cenário de organização do patrimônio arqueológico no processo de formação do conhecimento e da identidade brasileira, Bruno (1995) insere os registros arqueológicos no campo das "memórias exiladas", demonstrando que nas interpretações sociais acerca das questões culturais do país, o patrimônio arqueológico tem ocupado papel coadjuvante.

Não se pretende pormenorizar, aqui, os caminhos que distanciaram e/ou aproximaram os saberes e fazeres arqueológicos dos mesmos exercícios sociais de interpretação sobre seu conhecimento e reconhecimento cultural, mas observar que sua interface com a Museologia e a sociedade tem sido discutida por diversos olhares, como BRUNO, 1992, 1995, 1996, 2005, 2013-2014; CÂNDIDO, 2004, 2005; MORAES WICHERS, 2010, 2011; SALADINO, 2010; TAMANINI, 1994; dentre outros.

A classificação dos bens arqueológicos enquanto patrimônio cultural se faz por sua natureza intrínseca, ou seja, ela ocorre independentemente de sua inserção institucional, pois vincula diretamente este bem aos mecanismos de patrimonialização. Por patrimonialização, entende-se:

$\mathrm{O}$ ato que incorpora à dimensão social o discurso da necessidade do estatuto da Preservação. Conservação a ser praticada por instância tutelar, 
portanto, dotada de responsabilidade (competência) para custodiar os bens. E conservar, conceito que sustenta o Patrimônio, consiste em proteger o bem de qualquer efeito danoso, natural ou intencional, com intuito não só de mantê-lo no presente, como de permitir sua existência no futuro, ou seja, preservar. E a palavra salvaguarda, tão usada pelas entidades competentes nos seus documentos normativos, exprime, adequadamente, o pensamento e a ação que aplicam. (LIMA, 2012, p. 34).

Assim, é interessante notar que como bem da União, o patrimônio arqueológico, diferentemente de outros segmentos patrimoniais, estará sempre "patrimonializado", ou nos termos da legislação recente, "acautelado", mas poucas vezes "musealizado", quando consideramos toda a cadeia operatória museológica.

Quando a instância tutelar que assume a custódia destes bens se caracteriza como uma instituição ou entidade que aciona o que se denomina "ações museológicas", os mecanismos referentes à patrimonialização intercalam sua aplicabilidade por meio do processo de musealização. Para Desvallées e Mairesse (2013, p. 57), a patrimonialização descreve a ideia essencial de preservação de um objeto ou lugar, mas esta não resume o conjunto do processo museológico. Por sua vez, tanto os procedimentos quanto as finalidades que caracterizam a patrimonialização e a musealização de bens culturais são comuns, porém como ressalta Lima (2012, p. 36), a patrimonialização não se dá exclusivamente no âmbito da perspectiva museológica.

Desse modo, observa-se que os dois procedimentos se qualificam com as mesmas finalidades, mas a escolha pela musealização do patrimônio arqueológico se justifica por auxiliar na ampliação e ressignificação dos processos de patrimonialização incididos sobre este bem. Musealizar, como aponta os autores supracitados, não consiste meramente na transferência de um objeto para os limites físicos de um museu, já que, por meio desta transição de contextos, opera-se também uma mudança no próprio estatuto do objeto (DESVALLÉES e MAIRESSE, 2013, p. 57).

O processo de musealização inicia-se a partir do momento em que os objetos são separados de seu contexto de origem para serem estudados como documentos representativos da realidade que eles constituíam. Para Meneses (1994), a transformação do objeto em documento é o eixo da musealização, e "para se resumir um complicado problema à sua mínima expressão, no nível empírico pode-se dizer que documento é um suporte de informação" (MENESES, 1994, p. 21). Assim, um objeto inserido na lógica da musealização não se estabelece exclusivamente por seus usos, mas também pelos significados decorridos a partir deles, transmitindo um testemunho documental sobre a realidade. 
Um objeto separado do contexto do qual foi retirado não é nada além de um substituto dessa realidade que ele deve testemunhar. Essa transferência, por meio da separação que ela opera com o meio de origem, leva necessariamente a uma perda de informações que se verifica, talvez de maneira mais explícita, nas escavações arqueológicas clandestinas, uma vez que o contexto do qual os objetos são retirados é totalmente evacuado. É por esta razão que a musealização, como processo científico, compreende necessariamente o conjunto das atividades do museu: um trabalho de preservação (seleção, aquisição, gestão, conservação), de pesquisa (e, portanto, de catalogação) e de comunicação (por meio da exposição, das publicações etc.). (DESVALLÉES e MAIRESSE, 2013, p. $58)$.

Em síntese, entende-se o processo de musealização como uma série de ações sobre os objetos, quais sejam: aquisição, pesquisa, conservação, documentação e comunicação (CURY, 2005, p. 26). Entende-se também que, a comunicação não é o estágio final do processo de musealização, visto que, depois da aquisição/seleção, o tratamento técnico dado ao objeto será executado de acordo com uma série de condições dispostas pela instituição, que não necessariamente o fará na ordem: pesquisa, conservação, documentação e comunicação, podendo de acordo com os procedimentos políticos de avaliação interna, destinar o objeto a outros fins que não o expositivo, como parte de uma política de descarte (venda/permuta), ou mesmo direcionando-o à reserva técnica, por exemplo. É também a partir da comunicação que o patrimônio restabelece seus vínculos sociais, inserindo-se na lógica de um discurso ou servindo à elaboração de novas propostas discursivas.

Frente às características apresentadas, a escolha do caminho museológico como forma de inclusão do patrimônio arqueológico pode se dar por demandas de nível técnicocientífico e/ou sociocultural. Técnicas ou científicas, quando da aplicação de procedimentos específicos que expõem esses bens a verificações analíticas e, socioculturais quando, a partir destas verificações, têm-se a possibilidade de chamar à baila diversas interpretações concernentes a estes bens, na medida em que seus conhecimentos tomam, ou deveriam tomar a dimensão pública.

Para Rússio (1981/2012), o objeto de estudo da museologia é o fato museal ou fato museológico. "O fato museológico é a relação profunda entre o homem - sujeito conhecedor -, e o objeto, parte da realidade sobre a qual o homem igualmente atua e pode agir" (RÚSSIO, 1981, p. 53). De modo semelhante, a Arqueologia entendida como "a disciplina que investiga a emergência, a manutenção e a transformação dos sistemas socioculturais através dos tempos, por meio da cultura material por eles produzida" (LIMA, 2011 , p.12), opera, fundamentalmente, a partir das representações que estruturam a relação do homem com seu meio. 
Por esse prisma, de acordo com Bruno (2007), a Musealização da Arqueologia envolve uma cadeia operatória composta por

\begin{abstract}
procedimentos museológicos de salvaguarda (conservação e documentação) e comunicação (exposição e ação educativo-cultural), aplicados à realidade arqueológica, constituída a partir de referências patrimoniais, coleções e acervos. Por um lado, estes estudos buscam o gerenciamento e preservação destes bens patrimoniais e, por outro, têm a potencialidade de cultivar as noções de identidade e pertencimento. (BRUNO, 2007, p. 01 apud MORAES WICHERS, 2010, p. 47).
\end{abstract}

Como apontado anteriormente, os artefatos revelados pela arqueologia constituem material significante para os segmentos de valorização patrimonial de um território. Essa conexão de reconhecimento e valorização, ou seja, da inserção do bem arqueológico na lógica do discurso patrimonial, ocorre efetivamente por meio da Museologia. Por esse prisma, nota-se que as ações museológicas apresentam condições próprias e necessárias de sequenciar a cadeia operatória de processamento do material arqueológico, iniciada nos procedimentos de evidenciação destes materiais, indo até à sua comunicação social.

Nesse contexto, a Musealização da Arqueologia está comprometida com o estabelecimento de vínculos que aproximem os vestígios arqueológicos herdados das sociedades contemporâneas, considerando a diversidade de fatores históricos e socioculturais que influenciam essas aproximações e, ainda, com a busca de procedimentos técnico-científicos que permitam a realização de ações de salvaguarda e comunicação dos bens patrimoniais arqueológicos. (BRUNO, 2013-2014, p. 09).

A relação entre Arqueologia e Museologia não se finda na inserção de contextos materiais promovidos pela prática arqueológica por meio dos mecanismos de musealização. Ao contrário, trata-se de reconhecer que a musealização é o ponto de partida para a implantação de medidas mais eficazes de proteção, ou seja, o início de novos procedimentos, direcionados por um olhar amplo, híbrido e multifocal. No tocante aos acervos provenientes do licenciamento ambiental destacam-se questões relevantes e estruturais.

Muitas vezes, os materiais gerados não se destinam às instituições que apresentam, em sua natureza organizacional e prática de atuação, as possibilidades de continuidade dos mecanismos de preservação, processamento técnico e comunicação, previstos no processo de musealização, sendo estas instituições museus ou não. Outro ponto é a própria fragilização institucional nos processos de licenciamento em que os espaços de guarda figuram como mera formalidade ou em segundo plano, tornando-se gestores passivos de coleções passivas tanto por falta de condições estruturais e de recursos humanos na 
implantação de tais procedimentos quanto por trabalhar as coleções arqueológicas de forma desvinculada dos processos de construção do conhecimento local, da gestão dos territórios e das apropriações da paisagem cultural.

Dessa forma, ao lidar com as tensões do passado e do presente, a Musealização da Arqueologia trabalha não apenas com a identidade, mas também com a diferença, com a tensão e com os paradoxos da memória. Os milhares de vestígios advindos das pesquisas arqueológicas, agora definitivamente espalhadas por todo o Brasil, ganham sentido quando explorados a partir de uma perspectiva museológica contemporânea, que visa à construção de uma nova prática social. (MORAES WICHERS 20132014, p. 22).

O que se destaca diante das perspectivas apresentadas é que, seja aplicada aos contextos territoriais e comunitários, seja vinculada aos processos institucionais de preservação do patrimônio arqueológico, a Musealização da Arqueologia não conta com metodologias acabadas ou receitas aplicáveis a diferentes contextos. Existem fatores estruturantes que a compõem, mas justamente por se tratar de um sistema híbrido e que se pretende multivocal, este instrumento caracteriza-se como um processo de trabalho, uma alternativa aos caminhos percorridos pelo patrimônio arqueológico, convidando os atores sociais que o formam à sua participação ativa e sua execução sincrônica.

\section{CONSIDERAÇÕES FINAIS}

A preservação do patrimônio arqueológico brasileiro está em um processo contínuo de construção teórico-conceitual e de estratégias administrativo-jurídicas que assegurem a manutenção das ações de salvaguarda e socialização destes bens, compreendidos como parte do processo de conhecimento e reconhecimento das dinâmicas de organização da humanidade em seu espaço e tempo.

Assim, diante das inúmeras coleções que se encontram atualmente depositadas nas reservas técnicas ou nos corredores institucionais de centros de pesquisa, vislumbra-se que além de procedimentos estruturais urgentes e necessários ao manejo e preservação desse patrimônio, destacamos também a necessidade da execução de ações que efetivem o reconhecimento do contexto arqueológico no âmbito das relações sociais, pensando sua inserção em uma lógica territorial que explicite as dinâmicas de sua formação.

O desenvolvimento de ações museológicas aplicadas nos contextos arqueológicos, principalmente no tocante aos acervos provenientes dos processos de licenciamento, deve possibilitar a ampliação da noção de conhecimento, trabalhando as múltiplas vocalidades e proporcionando aos artefatos um contexto de ressignificação, fazendo com que estes artefatos não sejam "apropriados como materializações destacadas da categoria \begin{tabular}{|l|l|l|l|l|l|l|}
\hline (C) Rev. Arqueologia Pública & Campinas, SP & v.11 & n.2 & p. 180 & Novembro/2017 & ISSN 2237-8294 \\
\hline
\end{tabular} 
'patrimônio', mas enganchadas nas paisagens cotidianas das comunidades" (BEZERRA, 2013, p. 108).

Fazer do patrimônio arqueológico vetor de transformação sociocultural é inseri-lo como proposta concreta no âmbito dos projetos de pesquisa científica e preventiva, permitindo a cada representante uma atuação dialógica e descentralizada. No caso dos processos de licenciamento, tal prática infere no processo de organização e fiscalização das ações de empreendedores, profissionais e instituições, não somente segundo a lógica dos valores monetários, mas também pelo crivo dos valores culturais.

Portanto, diante dos consensos e contrassensos epistemológicos que caracterizam a arqueologia brasileira, o patrimônio arqueológico e as coleções a partir das quais este se organiza devem ser compreendidos pelo espectro das ampliações mais recentes sobre o conceito e as categorias de "patrimônio" (ou mesmo de "coleção").

A ascensão exponencial dessa tipologia de patrimônio, apesar de gerar consigo a formulação de mecanismos jurídico-administrativos, ainda carece de um esforço conjunto dos agentes envolvidos para a formulação de uma Política Pública Nacional em Arqueologia, política esta que se coloque de fato como a base dos tratamentos dispensados a estes bens, evitando que suas atribuições estejam a cargo somente dos instrumentos administrativos e da subjetividade de seus aplicadores. Desse modo, diante do histórico de conflitos, avanços e fragilidades das ações de salvaguarda do patrimônio arqueológico brasileiro, a lógica futura das ações para sua preservação e uso deverá ser construída essencialmente de forma consciente, crítica e coletiva.

\section{REFERÊNCIAS BIBLIOGRÁFICAS}

BEZERRA, M. Os Sentidos Contemporâneos das Coisas do Passado: reflexões a partir da Amazônia. Revista de Arqueologia Pública. Campinas, n .07, p. 107-122, 2013.

BRASIL. Instituto do Patrimônio Histórico e Artístico Nacional. Dispõe sobre procedimentos para solicitação de movimentação de bens arqueológicos em território nacional. Portaria no 195, de 18 de maio de 2016. Diário Oficial da União, Brasília, DF, 23 mai., 2016. Seção 01 , p. 83.

BRASIL. Instituto do Patrimônio Histórico e Artístico Nacional. Dispõe sobre a conservação de bens arqueológicos móveis, cria o Cadastro Nacional de Instituições de Guarda e Pesquisa, o Termo de Recebimento de Coleções Arqueológicas e a Ficha de Cadastro de Bem Arqueológico Móvel. Portaria no 196, de 18 de maio de 2016. Diário Oficial da União, Brasília, DF, 23 mai., 2016. Seção 01, p. 84. 


\section{Revista de Arqueologia Pública}

BRASIL. Instituto do Patrimônio Histórico e Artístico Nacional. Dispõe sobre Procedimentos para Solicitação de Remessa de Material Arqueológico para Análise no Exterior. Portaria no 197, de 18 de maio de 2016. Diário Oficial da União, Brasília, DF, 23 mai., 2016. Seção 01 , p. 87.

BRASIL. Instituto do Patrimônio Histórico e Artístico Nacional. Estabelece procedimentos administrativos a serem observados pelo IPHAN nos processos de licenciamento Ambiental dos quais participe. Instrução Normativa nº 01, de 25 de março de 2015. Diário Oficial da União, Brasília, DF, 26 mar., 2015. Seção 01. p. 11.

BRASIL. Instituto do Patrimônio Histórico e Artístico Nacional. Portaria no $\mathbf{2 3 0}$, de 17 de dezembro de 2002. Diário Oficial da União, Brasília, DF, 18 dez., 2002. Seção 01. p. 32.

BRASIL. Lei no 3.924, de 26 de julho de 1961. Dispõe sobre os monumentos arqueológicos e pré-históricos. Diário Oficial da União, Brasília, DF, 27 jul. 1961. Seção 01. p. 6793.

BRASIL. Ministério do Meio Ambiente. Estabelece procedimentos administrativos que disciplinam a atuação dos órgãos e entidades da administração pública federal em processos de licenciamento ambiental de competência do Instituto Brasileiro do Meio Ambiente e dos Recursos Naturais Renováveis - Ibama. Portaria Interministerial no 60, de 24 de março de 2015. . Diário Oficial da União, Brasília, DF, 25 mar., 2015. Seção 01. p. 71.

BRASIL. Secretaria do Patrimônio Histórico e Artístico Nacional. Portaria no 07, de 01 de dezembro de 1988. Diário Oficial da União, Brasília, DF, 15 dez., 1988.

BRUNO, M. C. O. Arqueologia e antropofagia: a musealização dos sítios arqueológicos. Revista do Serviço do Patrimônio Histórico e Artístico Nacional, n. 31, p. 234-247, 2005.

Arqueologia e Museu: Por quê? Para quem? Terra Indígena, n. 65, p. 37-43, 1992.

As futuras gerações têm direito à herança arqueológica? Premissas e desafios dos processos de musealização. In: MACHADO, G.; SOUZA, F. C. A.; STEINBACH, J. (Orgs.). Educação patrimonial e arqueologia pública: experiências e desafios. Itajaí: Casa Aberta Editora, 2013, p. 21-39.

Musealização da Arqueologia: caminhos percorridos. Revista de Arqueologia, v. 26, n.02 / v. 27, n. 01, Sociedade de Arqueologia Brasileira - SAB, p. 0415, 2013-2014.

\begin{tabular}{|l|l|l|l|l|l|l|}
\hline (C) Rev. Arqueologia Pública & Campinas, SP & v.11 & n.2 & p. 182 & Novembro/2017 & ISSN 2237-8294
\end{tabular}


Paranapanema. 1995. Tese (Doutorado), Faculdade de Filosofia, Letras e Ciências Humanas da Universidade de São Paulo, São Paulo, 1995.

Museologia e Museus: os inevitáveis caminhos entrelaçados. Cadernos de

Sociomuseologia, Lisboa, n.25, p. 5-20, 2006.

- Museus de Arqueologia: uma história de conquistadores, de abandono, de mudança. Revista do Museu de Arqueologia e Etnologia, n.6, p. 293-313, 1996.

Os percursos entre o endosso institucional e a musealização dos vestígios arqueológicos: por onde nos levam estes caminhos labirínticos. MENDONÇA, E. de C. GUIMARÃES E SILVA, J. G. da C. (orgs). Bens Culturais Musealizados: políticas públicas, preservação e gestão. Rio de Janeiro: UNIRIO / Escola de Museologia, 2014, p. 73-77.

CÂNDIDO, M. M. D. Arqueologia Musealizada: Patrimônio Cultural e Preservação em Fernando de Noronha. 2004. Dissertação (Mestrado) Programa de Pós-Graduação em Arqueologia, Museu de Arqueologia e Etnologia, Universidade de São Paulo, São Paulo, 2004.

Cultura Material: interfaces disciplinares da Arqueologia e da Museologia.

Cadernos do CEOM, v. 18, n. 21, p. 75-90, 2005.

CONSELHO NACIONAL DO MEIO AMBIENTE. Dispõe sobre critérios básicos e diretrizes gerais para a avaliação de impacto ambiental. Resolução CONAMA n 01, de 23 de janeiro de 1986. Resoluções do CONAMA: resoluções vigentes publicadas entre setembro de 1984 e janeiro de 2012. Ministério do Meio Ambiente. Brasília: MMA, 2012, p. 644-652.

CURY, Marília Xavier. Exposição - Concepção, Montagem e Avaliação. São Paulo: Annablume, 2005, 162p.

DESVALLÉES, A.; MAIRESSE, F. (ed.) Conceitos-chave de Museologia. Tradução de SOARES, B. B. e CURY, M. X. São Paulo: Comitê Brasileiro do Conselho Internacional de Museus: Pinacoteca do Estado de São Paulo: Secretaria de Estado da Cultura, 2013. 100 p. FUNARI, P.P. Arqueologia. São Paulo: Contexto. 2003. 126 p.

LIMA, D. F. C. Museologia-Museu e Patrimônio, Patrimonialização e Musealização: ambiência de comunhão. Boletim do Museu Paraense Emílio Goeldi - Ciências Humanas, Belém, v. 7, n. 1, p. 31-50, 2012. 
LIMA, T. A. Cultura material: a dimensão concreta das relações sociais. Boletim do Museu Paraense Emílio Goeldi - Ciências Humanas, v. 6, n. 1, p. 11-23, 2011.

MENESES, U. T. B. de. Do teatro da memória ao laboratório da História: a exposição museológica e o conhecimento histórico. Anais do Museu Paulista. Nova Série, São Paulo, v.02, p. 09-42, 1994.

MENESES, U. T. B. de. Premissas pra Formulação de Políticas Públicas em Arqueologia. Revista do Patrimônio Histórico e Artístico Nacional, Brasília: IPHAN, n. 33, p. 37-57, 2007.

MORAES WICHERS, C. A. de. Dois enquadramentos, um mesmo problema: os desafios da relação entre museus, sociedade e patrimônio arqueológico. Revista de Arqueologia, v. 26, n.02 / v. 27, n.01, Sociedade de Arqueologia Brasileira - SAB, p. 16-39, 2013-2014.

Museus e Antropofagia do Patrimônio Arqueológico: (des)caminhos da prática brasileira. 2010. Tese (Doutorado), Programa de Pós-Graduação em Museologia, Universidade Lusófona de Humanidades e Tecnologias, Lisboa, 2010. 460 p.

Patrimônio Arqueológico Paulista: proposições e provocações museológicas. 2011. Tese (Doutorado), Programa de Pós-Graduação em Arqueologia, Museu de Arqueologia e Etnologia, Universidade de São Paulo, São Paulo, 2011.

RÚSSIO, W. L'Interdisciplinarité em Muséologie (trad.). BRUNO, M. C. O. (org). Waldisa Rússio Camargo Guarnieri - textos e contextos de uma trajetória profissional. São Paulo: ICOM / Pinacoteca do Estado, 2010.

SALADINO, A. IPHAN, Arqueólogos e Patrimônio Arqueológico Brasileiro: um breve panorama. Revista de Arqueologia, v. 26, n. 02 / v. 27, n. 01, Sociedade de Arqueologia Brasileira - SAB, p. 40-58, 2013-2014.

Prospecções: o patrimônio arqueológico nas práticas e trajetória do IPHAN. Tese (Doutorado), Programa de Pós-Graduação em Ciências Sociais da Universidade do Estado do Rio de Janeiro. Rio de Janeiro: PPCIS/UERJ, 2010.

SCHAAN, D. P.; BEZERRA, M. (orgs.). Construindo a Arqueologia no Brasil: a trajetória da Sociedade de Arqueologia Brasileira. Belém: GKNoronha, 2009. 300 p.

SOARES, I. V. P. Proteção Jurídica do Patrimônio Arqueológico no Brasil: fundamentos para efetividade da tutela em face de obras e atividades impactantes. Erechim: Habilis, 2007. 228 p. 
Revista de Arqueologia Pública

TAMANINI, E. Museu arqueológico de Sambaqui: um olhar necessário. 1994. Dissertação (Mestrado), Programa de Pós-Graduação em Educação, Universidade Estadual de Campinas, Campinas, 1994. 169 p.

ZANETTINI, P. E. Projetar o futuro para a Arqueologia Brasileira: desafio de todos. Revista de Arqueologia Americana, v. 27, p. 71-84, 2009.

E. Qual futuro desejamos para a arqueologia no Brasil? Arqueologia em Debate. Jornal da Sociedade de Arqueologia Brasileira. São Paulo: SAB, n. 02, p.19-22, 2010.

ZANETTINI, P. E.; MORAES WICHERS, C. A. de. Arqueologia Preventiva e o Ensino de Arqueologia no Brasil. Habitus, Goiânia, v. 12, n. 2, p. 239-256, 2014. 